\title{
UM PROTOCOLO COM RETRANSMISSÕES MULTICÓPIAS PARA COMUNICAÇÕES VIA SATÉLITE A ALTAS VELOCIDADES*
}

\author{
Heliomar Medeiros de Lima \\ Banco do Brasil S. A. - UF Tecnologia - TECHS - DF \\ STN 716 - Bloco C - Térreo \\ CEP 70620-000 - Brasi1ia - DF \\ Otto Carlos Muniz Bandeira Duarte \\ Universidade Federal do Rio de Janeiro \\ COPPE/EE - Programa de Engenharia Elétrica \\ P.O. Box 68504 CEP 21945-970 - Rio de Janeiro - RJ - Brasil
}

\begin{abstract}
Resumo - Este artigo propõe e analisa o desempenho de um protocolo de retransmissão contínua (Go Back-N $\mathrm{GB}(\mathrm{N})$ ) adequado para comunicações de dados via satélite a altas taxas de transmissão. Sua idéia chave é o receptor armazenar as mensagens fora de sequiência recebidas corretamente após o envio de um pedido de retransmissão e o transmissor retransmitir múltiplas cópias das mensagens recebidas com erro, inclusive daquelas enviadas em avanço, para agilizar suas recuperações e diminuir o número total de retransmissões. Ao combinar o armazenamento das mensagens em avanço com a retransmissão de múltiplas cópias das mensagens reconhecidas negativamente, a estratégia reduz bastante, em relação a outros protocolos de retransmissão contínua, o número total de retransmissões envolvido na transferência de determinada quantidade de informações. Os resultados numéricos mostram que o protocolo proposto supera os melhores resultados conhecidos para esquemas de retransmissão contínua. Para ambientes com taxas de erros elevadas, o seu rendimento supera o desempenho de vários protocolos de retransmissão seletiva.
\end{abstract}

Abstract - This paper aims at presenting a variation of the Go-Back-N $(\mathrm{GB}(\mathrm{N}))$ ARQ protocol which operates with a receiver buffer and with multicopy retransmissions. The proposed strategy, that uses the key idea of the Weldon's scheme, avoids buffer overflows and reduces the effect of the round trip delay. Its throughput performance is analyzed using semi-Markov process. It improves significantly the throughput efficiency of the high speed satellite communications. The numerical results show that the new strategy presents a better performance than the best known $\mathrm{GB}(\mathrm{N})$ results. Furthermore, it outperforms many finite buffer selective-repeat ARQ, over a wide range of high bit error rates. The throughput efficiency remains in a usable range even for a very high error rate conditions.

Palavras-chave: Interconexão de redes, redes ATM, PSTN, redes IP.

* Este trabalho foi financiado pelo Banco do Brasil, UFRJ, CAPES, CNPq e FUJB.

\section{INTRODUÇÃO}

Um mecanismo de recuperação de erro é normalmente empregado para garantir uma transferência fim-a-fim confiável, se a taxa de erro residual da rede não satisfaz a qualidade de serviço requerida pela aplicação. A maioria dos sistemas de telecomunicações emprega o esquema de recuperação por retransmissão (ARQ - Automatic Request Repeat), devido a três razões principais: facilidade de implementação, robustez e confiabilidade. O esquema ARQ requer um canal de retorno para confirmar a recepção correta das mensagens ou pedir sua retransmissão e introduz um retardo na recuperação de uma mensagem recebida com erro, pelo menos igual ao tempo de ida e volta da comunicação (round trip delay). A correção automática (Forward Error Correction - FEC) e esquemas híbridos (FEC+ARQ) [1] requerem uma maior complexidade computacional e, portanto, são usados em aplicações específicas:

As técnicas de recuperação de erros por retransmissão podem ser classificadas em três métodos básicos: retransmissão pára-e-espera (SW - Stop and Wait); retransmissão contínua $(\mathrm{GB}(\mathrm{N})$ - Go Back-N) e retransmissão seletiva (SR - Selective Repeat). A retransmissão pára-e-espera é a mais simples de implementar, mas é bastante ineficiente, especialmente em comunicações onde o tempo de transmissão de uma mensagem é muito menor que o tempo de propagação, tal como ocorre no ambiente de satélite, a partir de médias velocidades, e em comunicações terrestres a altas velocidades. A retransmissão seletiva é a que apresenta o melhor rendimento $[2,3,4,5]$, mas é a de maior complexidade de implementação e exige grandes recursos de memória e de processamento. A retransmissão contínua é o método intermediário, tanto em termos de eficiência quanto em termos de requisitos de memória e processamento.

Uma das principais limitações do desempenho dos protocolos nas comunicações de dados a altas velocidades é o tempo envolvido no processamento de complexos mecanismos de recuperação de erros. O desenvolvimento de um protocolo fim-a-fim eficiente para esse ambiente deve levar em conta a simplicidade do seu mecanismo de correção de erros. A necessidade de uso de mecanismos simples de recuperação 
de erros aponta para o emprego de retransmissão contínua [6]. Adicionalmente, uma técnica utilizada para se conseguir um bom rendimento em condições de taxas de erros elevadas é a transmissão de múltiplas cópias da mesma mensagem.

A idéia de transmissões repetidas foi introduzida por Sastry [7], que propôs um protocolo de retransmissão contínua no qual o transmissor repete continuamente cada mensagem recebida com erro e reconhecida negativamente pelo receptor, até receber um reconhecimento positivo. Este esquema é melhor do que o $\mathrm{GB}(\mathrm{N})$ convencional apenas quando a taxa de erro do canal é muito alta. Em ambientes de satélite ou de altas velocidades, isto ocorre quando os rendimentos são muitos baixos e a utilização do protocolo não é prática. Birrel [8] apresentou uma outra estratégia na qual o transmissor sempre envia $m$ cópias de cada mensagem, mesmo na primeira transmissão. Se essas $m$ cópias são recebidas com erro, o transmissor volta a transmitir $m$ cópias dessa mensagem $e$ $m$ cópias daquelas enviadas por antecipação. Para $m \geq 2$, o rendimento fica penalizado mesmo em ambientes com taxas de erros muito baixas, visto que o rendimento máximo é $\frac{1}{m}$, para quaisquer taxas de erros. Outros esquemas com retransmissões repetidas foram também propostos em $[9,10]$, mas apresentando rendimento máximo muito baixo em ambientes de altas velocidades, inferior ao rendimento máximo do protocolo pára-e-espera.

Objetivando melhorar o desempenho dessas estratégias, o aumento da capacidade do receptor foi proposta por alguns autores. Nesta classe de protocolos, o receptor pode processar, armazenar e reconhecer mensagens livres de erros recebidas fora de sequiência. As mensagens são liberadas para o usuário quando as retransmissões restabelecem a sequiência original. Morris [11] apresentou expressão para o rendimento da estratégia de Sastry quando o receptor é dotado destas capacidades adicionais. Seu rendimento é sempre maior ou igual ao do $G B(N)$ convencional. A melhora de rendimento obtida é devida à eliminação da necessidade de retransmissão bem sucedida das mensagens já armazenadas no receptor.

Uma séria desvantagem das estratégias de recuperação de erros que retransmitem continuamente cópias de uma mesma mensagem é a retransmissão desnecessária de $S$ cópias que são descartadas pelo receptor após a recepção correta da mensagem solicitada. Os esquemas propostos em $[7,11]$ executam uma série de retransmissões consecutivas, até receber um reconhecimento positivo, para cada mensagem errada. Assim, há uma perda de banda passante do canal de $S$ mensagens para cada mensagem recebida com erro. O protocolo de Morris Modificado [12], proposto por De Lima e Duarte, reduz o número de séries de retransmissões consecutivas e apresenta rendimento até $20 \%$ superior ao do esquema proposto por Morris. Para comunicações ponto-a-multiponto, De Lima e Duarte [13] propõem dois esquemas que retransmitem continuamente cópias de uma mesma mensagem.

O protocolo SETRAN [14], proposto por Lin e Yu, é um esquema de retransmissão contínua que também processa, armazena e reconhece positivamente as mensagens livres de erros recebidas fora de sequiência. Neste esquema, as mensagens enviadas em avanço e recebidas corretamente (e portanto armazenadas na memória tampão do receptor) não são retransmitidas. Nos espaços correspondentes às retrans- missões dessas mensagens, o transmissor retransmite cópias da mensagem mais antiga na fila de retransmissão. Além disso, quando não há mais mensagens a retransmitir, entre aquelas enviadas em avanço, o transmissor repete continuamente a mensagem mais antiga na fila de retransmissão até receber seu reconhecimento positivo. Note-se que neste esquema apenas as mensagens reconhecidas negativamente são retransmitidas.

Miller e Lin [15] introduziram o uso de retransmissōes repetidas nas estratégias de retransmissão seletiva, propondo os esquemas $S R+S T$. No entanto, os melhores desempenhos com protocolos que usam retransmissões repetidas foram obtidos pelo esquema de retransmissão seletiva multifases e multicópias proposto por Weldon [16] e suas derivações $[17,18]$.

Este trabalho apresenta e analisa o desempenho de um esquema de retransmissão contínua, com memória no receptor, no qual o transmissor retransmite $m$ cópias, $m \geq 2$, das mensagens recebidas com erro e reconhecidas negativamente. Sua idéia chave é armazenar as mensagens recebidas corretamente após o envio de pedido de retransmissão, eliminando assim a necessidade de retransmissāo correta dessas mensagens, e enviar múltiplas cópias não apenas da mensagem mais antiga na fila de retransmissão, mas de todas as mensagens enviadas em avanço e recebidas com erro, para agilizar as suas recuperações e diminuir o número total de retransmissões. A estratégia proposta evita transbordos de memória e reduz o efeito do número de mensagens enviadas em avanço, $S$, tornando-o adequado para quaisquer sistemas onde o tempo de propagação do canal é longo em relação ao tempo de transmissão de uma mensagem. O esquema requer uma memória para $S+1$ mensagens no transmissor e no receptor.

Inicialmente, descreve-se o modelo matemático, baseado em processos semi-Markovianos de parâmetro discreto, utilizado para analisar o desempenho da estratégia proposta. $\mathrm{Na}$ Seção 3 é apresentada uma descrição da estratégia proposta e analisado o seu desempenho. Os resultados numéricos, apresentados e discutidos na Seção 4, mostram um melhor desempenho da estratégia proposta em relacão aos melhores resultados conhecidos para esquemas de retransmissão contínua, para qualquer taxa de erro. Para um ambiente com taxas de erros elevadas, o seu rendimento supera inclusive o desempenho de alguns protocolos de retransmissão seletiva "não ideais" $[15,16,19]$. Por último, as principais conclusões deste trabalho são apresentadas.

\section{MODELO MATEMÁTICO}

O rendimento é a relação entre o número de mensagens liberadas, em sequiência para o usuário, pelo receptor, e o número total de mensagens transmitidas e retransmitidas.

Para calcular o rendimento da estratégia proposta, definem-se estados para o receptor, de acordo com a existência de procedimento de recuperação de erros, e calcula-se a probabilidade do receptor estar em cada estado, bem como o rendimento do protocolo em cada um dos estados.

O rendimento do protocolo será obtido pela média ponderada dos rendimentos em cada estado, onde os pesos são as 
probabilidades do receptor estar no respectivo estado. Por sua vez, essas probabilidades dependem das probabilidades condicionais de transição de um estado para outro e dos tempos de espera nesses estados.

Para calcular as probabilidades do receptor se encontrar em cada estado, modela-se seu comportamento por um processo semi-Markoviano de parâmetro discreto [20], cuja sequência de de estados é representada por:

$$
X(0), X(1), X(2), X(3), \ldots, X(n), X(n+1), \ldots
$$

onde $X(n), n=0,1,2, \ldots$, é uma variável aleatória que indica o estado do receptor após a recepção da n-ésima mensagem.

Os dados são transmitidos em forma de mensagens de informação.

Através de canal de retorno separado, o receptor envia reconhecimentos para o transmissor. Se a mensagem de número $\mathrm{N}(\mathrm{R})$ é recebida com erro, o receptor envia um pedido de retransmissão (REJ N(R) reject) solicitando a retransmissão dessa mensagem e de todas as outras enviadas em avanço. Através do reconhecimento positivo (RR $N(R)$ receiver ready), o receptor informa que as mensagens de informação com número de sequiência menor do que $N(R)$ foram recebidas corretamente.

$\mathrm{Na}$ avaliação de desempenho são adotadas as seguintes premissas:

- os reconhecimentos são recebidos sem erros;

- todas as mensagens de informação têm o mesmo comprimento L;

- há sempre uma nova mensagem para ser transmitida no transmissor;

- o número de mensagens enviadas em avanço é constante e igual a $S\left(\frac{R T}{L} \leq S \leq \frac{R T}{L}+1\right.$, onde $R$ é a taxa de transmissão e $T$, o tempo de propagação (ida e volta));

- a ocorrência de erros nos diversos bites são eventos estatisticamente independentes. Assim, a probabilidade de uma mensagem ser recebida com erro pelo receptor, denotada por $P_{b e}$, é independente de mensagem para mensagem. Adicionalmente, a probabilidade de uma mensagem ser recebida corretamente pelo receptor é denotada por $P_{b c}$;

- tanto o transmissor quanto o receptor têm uma memóriatampão para $S+1$ mensagens.

\section{O PROTOCOLO PROPOSTO}

A estratégia proposta é o resultado da aplicação da idéia de retransmissões multicópias, introduzida por Weldon, ao protocolo REJ Estendido [12] e é destinada a uso em comunicações via satélite, a partir de médias velocidades, e em comunicações terrestres a altas velocidades em ambientes não livre de erros. Sua idéia chave é armazenar as mensagens em avanço recebidas corretamente após o envio de pedido de retransmissão, eliminando assim a necessidade de retransmissão correta dessas mensagens e retransmitir $m$ cópias, $m \geq 2$, das mensagens reconhecidas negativamente, para agilizar suas recuperações e a conseqüente liberação das mensagens já armazenadas no receptor.
Ao detectar erro na mensagem de número $\mathrm{N}(\mathrm{R})$, o receptor inicia um procedimento de recuperação de erros enviando um pedido de retransmissão, guarda um espaço (lacuna) na sua memória e continua a processar as mensagens enviadas em avanço, armazenando aquelas recebidas corretamente, para liberação posterior. A cada mensagem recebida com erro, entre aquelas enviadas em avanço é deixado um espaço na memória do receptor.

As mensagens correspondentes aos espaços deixados na memória do receptor são chamadas mensagens $B_{e_{i}}, 0 \leq i \leq$ $S$. Portanto, após o envio do REJ N(R), que corresponde ao pedido de retransmissão da mensagem $B_{e_{0}}$, a primeira mensagem entre aquelas enviadas em avanço recebida com erro pelo receptor é chamada mensagem $B_{e_{1}}$. A segunda recebida com erro é chamada de mensagem $B_{e_{2}}$. E assim sucessivamente.

Ao enviar uma mensagem com número de seqüência $x$, o transmissor a mantém em sua memória em uma fila de retransmissão, até que todas as mensagens com número de sequiência menor ou igual a $x$ sejam reconhecidas positivamente pelo receptor. Adicionalmente, ao receber um primeiro pedido de retransmissão, REJ $B_{e_{0}}$, o transmissor inicia o primeiro ciclo de retransmissão, envia $m$ cópias da mensagem $B_{e_{0}}$ e passa a retransmitir as mensagens enviadas em avanço e armazenadas em sua fila de retransmissão (as mensagens de número $B_{e_{0}}$ até $B_{e_{0}}+S$ ). Se durante este ciclo de retransmissão o transmissor receber um REJ $B_{e_{i}}, 1 \leq i \leq S$, ele retransmite $m-1$ cópias adicionais dessa mensagem $B_{e_{i}}$.

Se as $m$ cópias da mensagem $B_{e_{0}}$ são recebidas com erro, o receptor envia um REJ $B_{e_{0}}$. O transmissor, ao receber esse REJ $B_{e_{0}}$, inicia um novo ciclo de retransmissão adotando um procedimento similar ao do primeiro ciclo. Durante os ciclos de retransmissão, o receptor só envia um REJ $B_{e_{i}}, 0 \leq i \leq S$, após detectar erros nas $m$ cópias da mensagem correspondente.

Cada vez que retransmite a mensagem $B_{e_{0}}$, o transmissor retransmite também as mensagens armazenadas em sua fila de retransmissão (com numeração entre $B_{e_{0}}$ e $B_{e_{0}}+S$ ) e $m-1$ cópias adicionais das mensagens $B_{e_{i}}, i \geq 1$, não recuperadas até o ciclo de anterior. Ao reenviar sempre as mensagens armazenadas em sua fila de retransmissão (observe-se que estas incluem uma cópia de cada mensagem $B_{e_{i}}, i \geq 1$, ), o transmissor elimina a necessidade do receptor enviar um reconhecimento a cada mensagem recebida, o que reduz 0 número de reconhecimentos enviados pelo receptor e processados pelo transmissor.

Após a recuperação da mensagem $B_{e_{0}}$, o receptor libera as mensagens armazenadas em sua memória, com numeração entre $B_{e_{0}}$ e a primeira $B_{e_{i}}$ ainda não recuperada (se houver) e passa a aguardar a retransmissão das $m$ cópias dessa mensagem $B_{e_{i}}$. Após recuperar essa mensagem $B_{e_{i}}$, o receptor passa a aguardar a mensagem $B_{e_{j}}, j \geq i$ ainda não recuperada (se houver). E assim sucessivamente até o preenchimento das lacunas existentes e a liberação das mensagens armazenadas em sua memória.

Se pelo menos uma mensagem $B_{e_{i}}$ não consegue ser recuperada durante os ciclos de retransmissão necessários à recuperação da mensagem $B_{e_{0}}$, a primeira mensagem $B_{e_{i}}$ tornase a nova mensagem $B_{e_{0}}$ e as lacunas existentes na memória 


\section{Heliomar Medeiros de Lima Um Protocolo com Retransmissões Multicópias para Comunicações Via Satélite a Altas Velocidades}

do receptor tornam-se $B_{e_{1}}, B_{e_{2}}, \ldots, B_{e_{j}}, j<S$. O receptor envia um REJ $B_{e_{0}}$ e passa a processar as mensagens enviadas em avanço em relação à nova mensagem $B_{e_{0}}$, armazenando aquelas recebidas corretamente (e ainda nâo armazenadas), passando a identificar novas mensagens $B_{e_{i}}$.

Ao contrário do que acontece no protocolo REJ Estendido [12], o receptor não limpa sua memória quando uma mensagem $B_{e_{i}}$ torna-se $B_{e_{0}}$ e um novo REJ $B_{e_{0}}$ é enviado.

\section{A ANÁLISE DE DESEMPENHO}

A estratégia proposta define dois estados para o receptor: o estado normal e o estado excepcional. No estado normal não existe nenhum procedimento de recuperação de erros em andamento (as eventuais mensagens anteriormente recebidas com erro já foram recuperadas) e não existe mensagens armazenadas na memória-tampão do receptor. No estado excepcional ou existe um pedido de recuperação em andamento ou existe alguma mensagem armazenada na memória do receptor dependendo da recuperação de uma mensagem anterior para poder ser liberada para o usuário.

O receptor passa do estado normal para o excepcional quando recebe uma mensagem com erro, a mensagem $B_{e_{0}}$. Define-se que a transição ocorre no início da recepção dessa mensagem. Adicionalmente, define-se que o estado excepcional tem um ciclo de transmissão e um ou mais ciclos de retransmissão. O ciclo de transmissão corresponde às $S+1$ mensagens recebidas, corretamente ou não, após a transição para o estado excepcional. A cada retransmissão contínua executada em resposta a um REJ $B_{e_{0}}$ corresponde um ciclo de retransmissão. Cada ciclo de retransmissão termina após a recepção da retransmissão da mensagem de número $N(R)+S$, onde $\mathrm{N}(\mathrm{R})$ é o número da mensagem cuja recepção com erro causou a transição do estado normal para o excepcional.

Durante o estado excepcional, o receptor só armazena as mensagens correspondentes ao ciclo de transmissão, isto é, as mensagens com número de sequência entre $N(R)$ e $N(R)+$ $S$. Somente após voltar ao estado normal é que o receptor pode armazenar as mensagens de número $N(R)+S+1$, $N(R)+S+2, \ldots$. Além disso, ao passar para o estado excepcional, o receptor permanence neste estado até que todas as mensagens correspondentes ao ciclo de transmissão sejam recebidas corretamente pelo receptor. Isto é, só sai após recuperar todas as mensagens $B_{e_{i}}, 0 \leq i \leq S$, definidas durante o ciclo de transmissão. Assim, durante o estado excepcional, são sempre transferidas $S+1$ mensagens para o receptor, as mensagens correspondentes ao primeiro ciclo do estado excepcional, o ciclo de transmissão.

A transição do estado excepcional para o normal ocorre após a recepção da retransmissão da mensagem de número $N(R)+S$, no último ciclo de retransmissão. Este último ciclo de retransmissão é aquele no qual é completada a recuperação das mensagens $B_{e_{i}}, 0 \leq i \leq S$, correspondentes ao ciclo de transmissão.

A Figura 1 ilustra o funcionamento do esquema proposto para $m=2$.

O rendimento da estratégia é dado por:

$$
\eta=P(N) \eta(N)+P(E) \eta(E)
$$

onde $P(N)$ e $P(E)$ são as probabilidades do receptor estar nos estados normal e excepcional, e $\eta(N)$ e $\eta(E)$ os rendimentos nos respectivos estados. Como foi definido que a transição para o estado excepcional ocorre imediatamente antes da recepção da mensagem errada, o rendimento do protocolo no estado normal é 1 (100\%).

Como durante o estado excepcional são transferidas $S+1$ mensagens, tem-se,

$$
\eta(E)=\frac{S+1}{E\left[t_{E}\right]}
$$

onde $E\left[t_{E}\right]$ é o tempo médio de espera no estado excepcional.

Do estado normal o receptor sempre passa para o estado excepcional e deste para o normal (não existem transições virtuais). Portanto, as probabilidades condicionais de transição de um estado para outro são:

$$
P(E \mid N)=P(N \mid E)=1
$$

Usando-se as propriedades do processo semi-Markoviano obtém-se as probabilidades do receptor se encontrar no estados normal e excepcional, em regime estacionário:

$$
\begin{aligned}
& P(N)=\frac{E\left[t_{N}\right]}{E\left[t_{N}\right]+E\left[t_{E}\right]}, \\
& P(E)=\frac{E\left[t_{E}\right]}{E\left[t_{N}\right]+E\left[t_{E}\right]} .
\end{aligned}
$$

Substituindo-se as equações 2,4 e 5 na equação 1 acima obtém-se:

$$
\eta=\frac{E\left[t_{N}\right]+S+1}{E\left[t_{N}\right]+E\left[t_{E}\right]} .
$$

O tempo médio de espera no estado normal é dado por :

$$
E\left[t_{N}\right]=\sum_{i=0}^{\infty} i P_{b e} P_{b c}^{i}=\frac{P_{b c}}{P_{b e}} .
$$

Substituindo-se esse tempo médio na equação 6 obtém-se:

$$
\eta=\frac{P_{b c}+P_{b e}(S+1)}{P_{b c}+P_{b e} E\left[t_{E}\right]} .
$$

O tempo médio de espera no estado excepcional é dado por:

$$
E\left[t_{E}\right]=\left(1+E\left[n_{e}\right]\right)(S+1)+E\left[t_{a}\right],
$$

onde $E\left[n_{e}\right]$ é o número médio de ciclos de retransmissão e $E\left[t_{a}\right]$ é o tempo médio de espera adicional devido à retransmissão das cópias adicionais das mensagens $B_{e_{i}}$.

O número médio de ciclos de retransmissão é dado por

$$
E\left[n_{e}\right]=\sum_{j=1}^{\infty} j \operatorname{Pr}\left\{n_{S+1}=j\right\},
$$




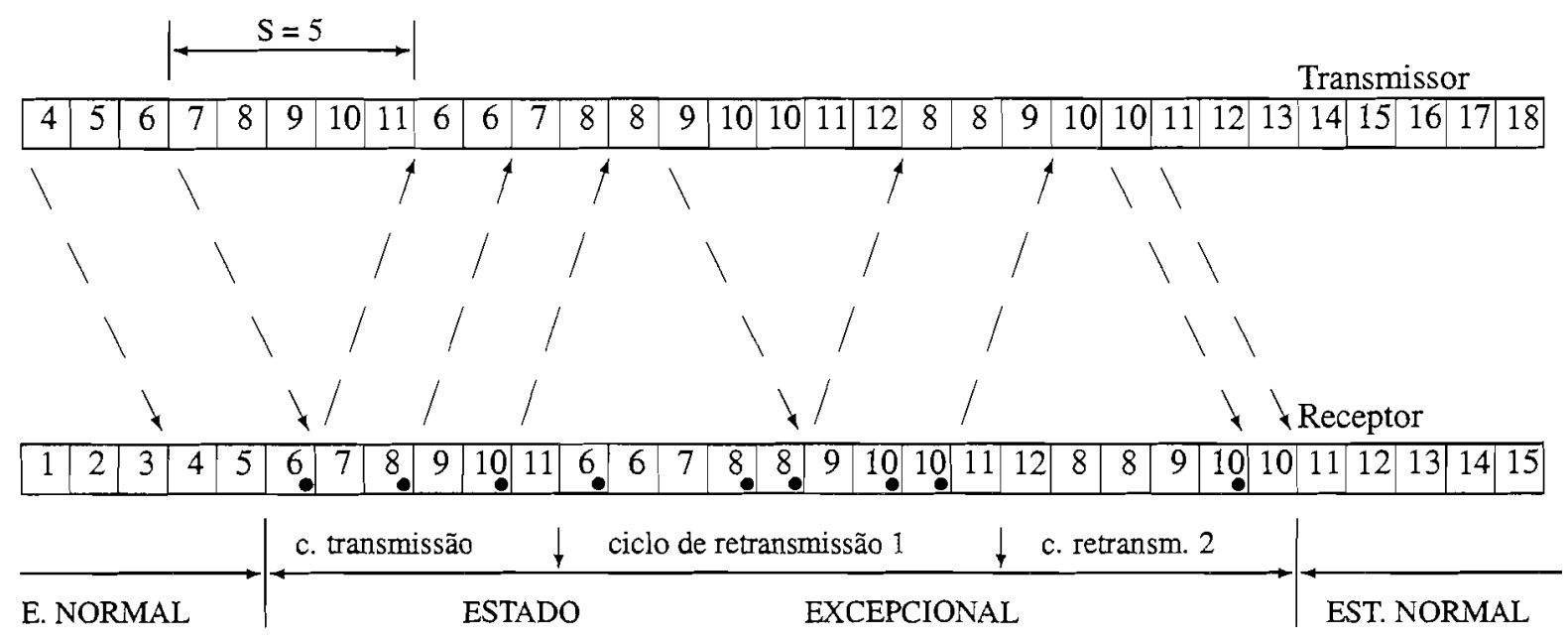

$$
\begin{aligned}
& 6 \text { - mensagem } B_{e_{0}} \\
& 8 \text { - mensagem } B_{e_{1}}
\end{aligned}
$$

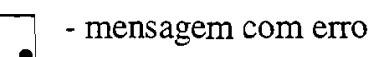

OBS: no primeiro ciclo de retransmissão, a mensagem 8 torna-se a nova mensagem $B_{e_{0}}$ e a 10 , a nova $B_{e_{1}}$.

Figura 1. A Estratégia Proposta

onde $\operatorname{Pr}\left\{n_{S+1}=j\right\}$ é a probabilidade da transferência das $S+1$ mensagens do ciclo de transmissão ser completada no j-ésimo ciclo de retransmissão. Isto é, a probabilidade dessa transferência ser completada no ciclo $j$ de retransmissão, dado que no ciclo : - 1 pelo menos uma das $S+1$ mensagens não havia sido recebida corretamente. Ou seja:

$$
\begin{gathered}
\operatorname{Pr}\left\{n_{S+1}=j\right\}= \\
=\operatorname{Pr}\left\{n_{S+1} \leq j\right\}-\operatorname{Pr}\left\{n_{S+1} \leq j-1\right\} .
\end{gathered}
$$

Não é difícil mostrar que:

$$
\begin{gathered}
\operatorname{Pr}\left\{n_{S+1} \leq j\right\}= \\
=\left(1-P_{b e}^{1+j m}\right)^{S} \frac{\left(1-P_{b e}^{1+j m)}\right)-P_{b c}}{1-P_{b c}}= \\
=\left(1-P_{b e}^{1+j m)}\right)^{S} \cdot\left(1-P_{b e}^{j m}\right),
\end{gathered}
$$

onde $\left(1-P_{b e}^{1+j m}\right)^{S}$ é a probabilidade das $S$ mensagens serem sido recebidas corretamente pelo receptor no ciclo $j$ de retransmissão ou nos ciclos anteriores (observe-se que essas mensagens podem ser recebidas corretamente inclusive no ciclo de transmissão) e

$$
\frac{\left(1-P_{b e}^{1+j m}\right)-P_{b c}}{1-P_{b c}}=1-P_{b e}^{j m}
$$

é a probabilidade da mensagem $\mathrm{N}(\mathrm{R})$ (mensagem $B_{e_{0}}$ do ciclo de transmissão) ser recebida corretamente no ciclo $j$ de retransmissão ou em ciclos anteriores, dado que ela foi recebida com erro no ciclo de transmissão.

Substituindo-se a Eq. 12 na Eq. 11 e esta na Eq. 10, obtém- se:

$$
\begin{aligned}
E\left[n_{e}\right]= & \sum_{j=1}^{\infty} j\left(\left(1-P_{b e}^{1+j m}\right)^{S}\left(1-P_{b e}^{j m}\right)\right)- \\
& -\sum_{j=1}^{\infty} j\left(\left(1-P_{b e}^{1+(j-1) m}\right)^{S}\left(1-P_{b e}^{(j-1) m}\right) j\right)
\end{aligned}
$$

Para calcular $E\left[t_{a}\right]$, é necessário calcular o tempo de espera adicional causado pela transmissão das cópias adicionais. No primero ciclo de retransmissão, cada uma das mensagens $B_{e_{i}}, 0 \leq i \leq S$, aumenta o tempo de espera do em $m-1$ unidades. Nos ciclos seguintes, apenas as mensagens não recuperadas nos ciclos anteriores aumentam o tempo de espera em até $m-1$ unidades cada uma. Logo, o tempo médio de espera devido à cópias adicionais de uma mensagem $B_{e_{j}}, 0 \leq j \leq S$ é dado por:

$$
E\left[t_{a_{j}}\right] \leq(m-1) E\left[n_{R E J B_{e_{i}}}\right] \sum_{i=j}^{S}\left(\begin{array}{c}
S \\
i
\end{array}\right) \cdot P_{b e}^{i} P_{b c}^{S-i}
$$

O número médio de ciclos de retransmissão necessários para recuperar uma mensagem $B_{e_{i}}$ corresponde ao número médio de REJ $B_{e_{i}}$ necessários para recuperar essa mensagem e é dado por:

$$
E\left[n_{R E J B_{e_{i}}}\right]=\sum_{i=1}^{\infty} i\left(1-P_{b e}^{m}\right) P_{b e}^{m(i-1)}=\frac{1}{1-P_{b e}^{m}}
$$

Finalmente, o tempo médio de espera adicional no estado 
Rendimento(\%)

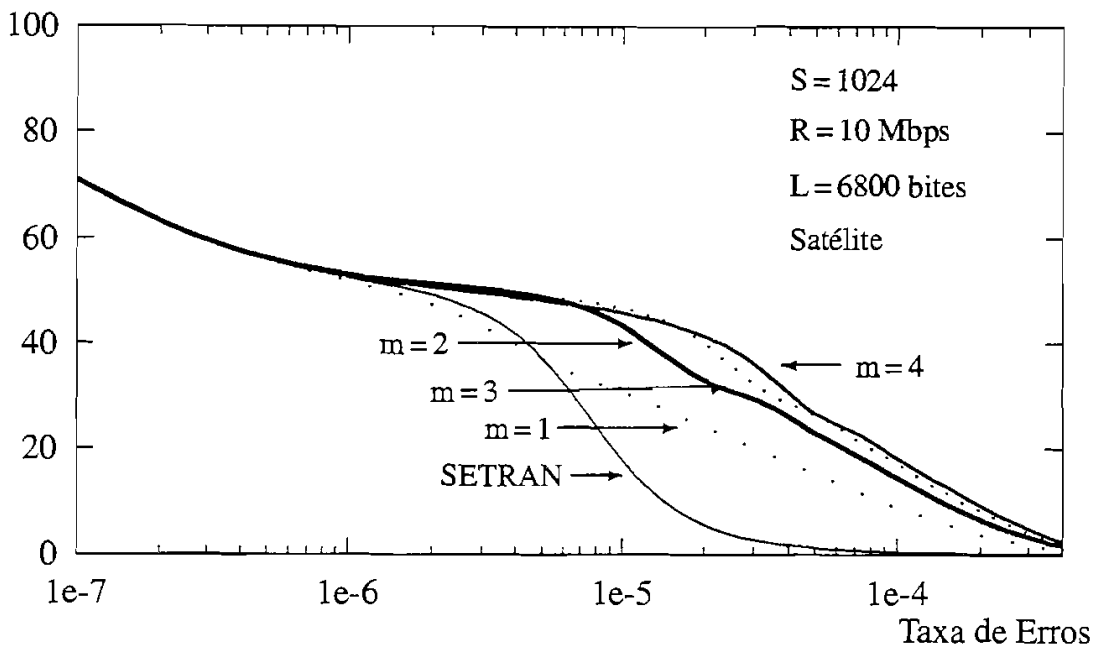

Figura 2. Comparação entre o esquema proposto e o esquema SETRAN.

\section{Rendimento(\%)}

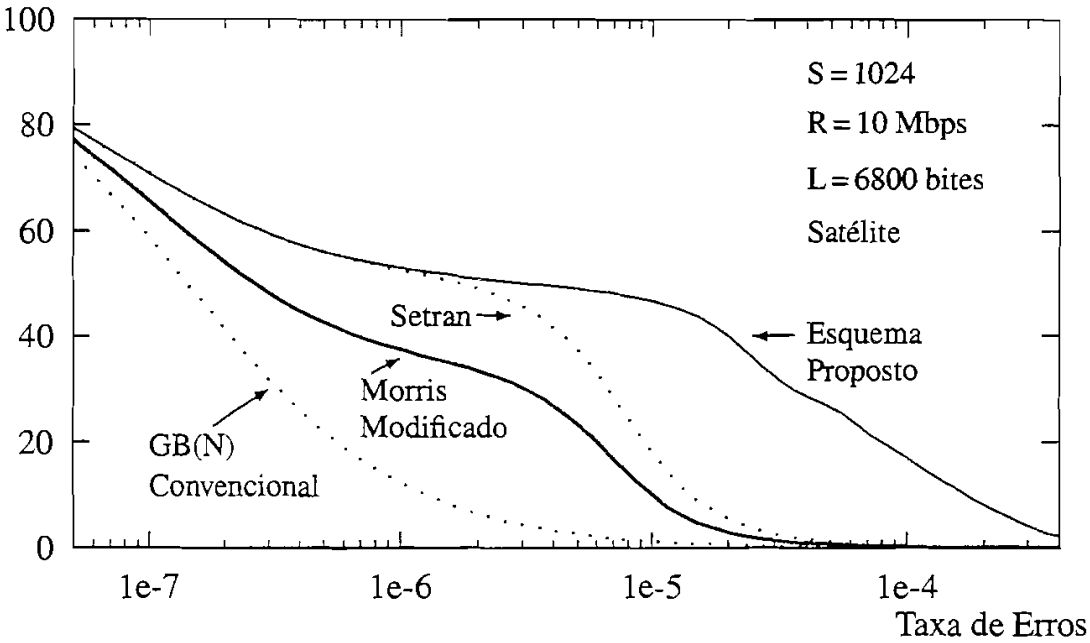

Figura 3. Rendimento do Esquema Proposto(m=3), SETRAN, Morris Modificado e do GB(N).

excepcional devido às cópias adicionais, $E\left[t_{a}\right]$, é dado por:

$$
\begin{aligned}
E\left[t_{a}\right] & =\sum_{j=0}^{S} E\left[t_{a_{j}}\right] \leq \\
& \leq \frac{m-1}{1-P_{b e}^{m}} \sum_{j=0}^{S} \sum_{i=j}^{S}\left(\begin{array}{c}
S \\
i
\end{array}\right) P_{b e}^{i} P_{b c}^{S-i}
\end{aligned}
$$

A partir da desigualdade acima, pode-se concluir que a sua substituição na Eq. ?? e desta na Eq. 8 leva, na verdade, a um limitante inferior (lower bound) do rendimento da estratégia proposta. Assim, seu rendimento é maior ou igual ao dado pela Eq. 8.

\section{RESULTADOS NUMÉRICOS}

A Figura 2 compara o rendimento da nova estratégia, para comunicações via satélite a $10 \mathrm{Mbps}, S=1024$ e $L=6800$ bites, para alguns valores do números de cópias $(m=1,2,3$ e 4), com o limitante inferior (lower bound) do esquema SETRAN. Observa-se que, para $m \geq 2$, o rendimento da nova estratégia supera o limitante inferior do SETRAN. Pode-se verificar ainda que com o aumento de $m$, a estratégia proposta apresenta um rendimento ligeiramente menor na região de médias taxas de erros com um ganho na região de taxas de erros elevadas. Entretanto, a melhora diminui à medida que $m$ aumenta. O melhor ganho de rendimento se consegue quando se passa de $m=1$ para $m=2$. Pode-se concluir que o uso de baixos valores de $m$ é a solução mais indicada. O novo esquema com $m=1$ é um caso particular do protocolo multiponto proposto em [21], quando se tem apenas um 
Rendimento(\%)

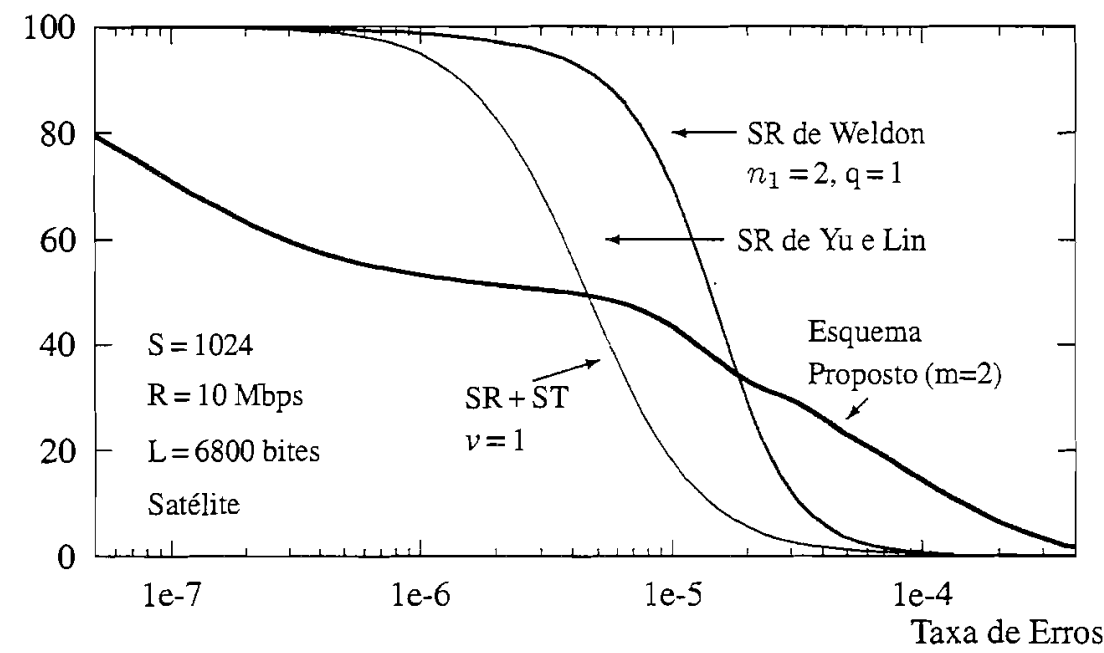

Figura 4. Rendimento do esquema proposto, do $S R+S T$ e dos SR de Weldon e Yu/Lin.

Rendimento(\%)

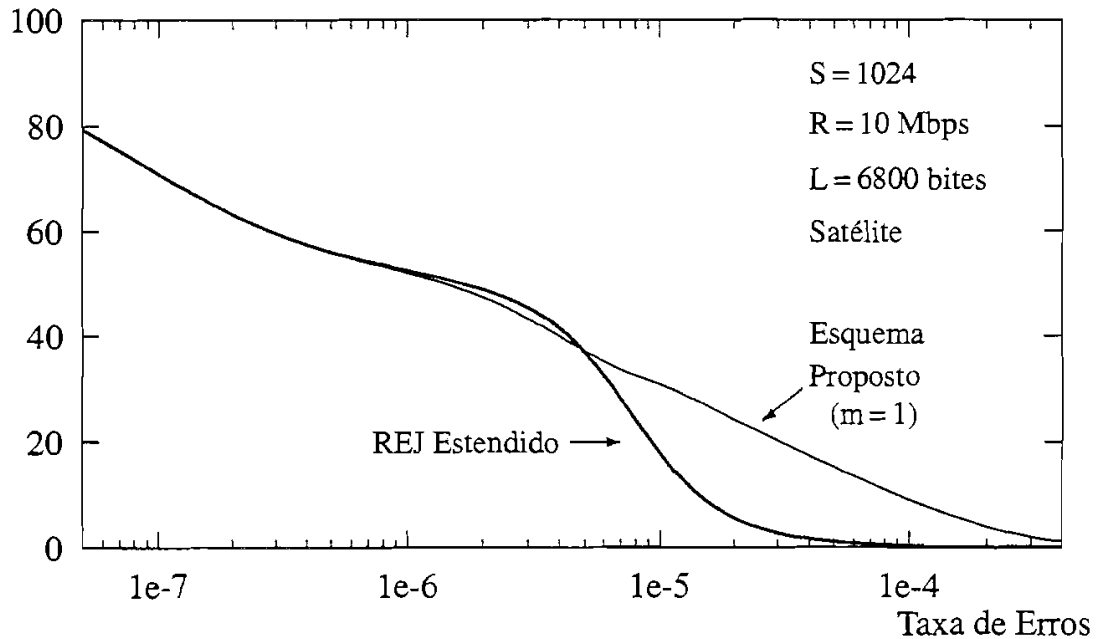

Figura 5. Comparação entre o esquema proposto $(m=1)$ e o REJ Estendido.

-eceptor.

A Figura 3 mostra, para comunicação via satélite a $10 \mathrm{Mbps}$, com $S=1024$ e $L=6800$ bites, o limitante injerior do protocolo SETRAN e os rendimentos da estratégia proposta, para $m=3$, do esquema de retransmissão contínua zonvencional e do protocolo de Morris Modificado. Verificase que o protocolo proposto apresenta rendimento superior :os dos outros esquemas de retransmissão contínua.

A Figura 4 compara o rendimento do novo esquema, para $\eta=2$, com os rendimentos de alguns protocolos de retransmissão seletiva: o esquema $S R+S T$ de Miller e Lin[15] quando este usa memórias para $2 . S$ mensagens no transmissor e no receptor $(v=1)$, o esquema de Weldon[16], quando este usa duas cópia nas retransmissões $\left(n_{1}=2\right)$ e memória para $2 . S+1$ mensagens no transmissor e $S+1$ no receptor $(q=1)$ e a estratégia de Yu e Lin [19], que usa memória para $2 S+1$ mensagens no transmissor e $S+1$ no receptor
Observa-se que a partir de uma certa taxa de erros, a nova estratégia apresenta melhor rendimento do que aqueles apresentados pelos citados esquemas de retransmissão seletiva: taxas de erros binários maiores do que $4,7 \times 10^{-6}$, e rendimentos menores do que $49 \%$ para o $S R+S T, 1,3 \times 10^{-5} \mathrm{e}$ $40 \%$ para o esquema de Yu e Lin, e $1,9 \times 10^{-5}$ e $34 \%$ para o esquema de Weldon. A partir dessas taxas de erros, as melhoras obtidas chegam aos seguintes valores: $28 \%$ em relação ao $S R+S T, 19 \%$ para o Yu e Lin, e $20 \%$ para o Weldon.

A Figura 5 compara o rendimento do novo esquema para $m=1$ com o do protocolo REJ Estendido [12], para comunicaçōes via satélite a $10 \mathrm{Mbps}$ com $S=1024$ e $L=6800$ bites. A diferença entre os dois protocolos é que no REJ Estendido o receptor limpa a sua memória, antes de enviar um REJ $B_{e_{i}}$, quando a mensagem $B_{e_{i}}$ não consegue ser recuperada pelos ciclos de retransmissão necessários à recuperação de $B_{e_{0}}$. Neste novo protocolo, o receptor não limpa sua 


\section{Heliomar Medeiros de Lima Um Protocolo com Retransmissões Multicópias para Comunicações Via Satélite a Altas Velocidades}

memória. Observe-se que não limpar a memória aumenta o rendimento nas altas taxas de erros. O desempenho um pouco menor apresentado as taxas de erros médias deve-se ao fato do receptor, mesmo tendo memória disponível, não armazenar as mensagens novas recebidas corretamente a partir do segundo ciclo de retransmissão mas não transmitidas no ciclo de transmissão.

\section{CONCLUSÃO}

Neste artigo apresentou-se e analisou-se o desempenho de um novo protocolo de retransmissão contínua para uso em comunicações via satélite a partir de médias velocidades e em comunicações terrestres a altas velocidades.

Os resultados obtidos são consideravelmente superiores aos melhores resultados conhecidos para esquemas de retransmissão contínua. Seu rendimento, para $m=4$, apresenta uma melhora de até $36 \%$ em relação ao limitante inferior do esquema SETRAN.

A estratégia proposta evita transbordos de memória e reduz o efeito de grandes números de mensagens em trânsito no canal, tal como ocorre em comunicações onde o tempo de transmissão de uma mensagem é muito menor do que o tempo de ida e volta da comunicação.

Foi mostrado que para ambientes com taxas de erros não muito baixas, o rendimento do esquema proposto supera o desempenho de vários protocolos de retransmissão seletiva "não ideais".

\section{REFERÊNCIAS}

[1] J. Nonnenmacher e E. W. Biersack, "Parity-based loss recovery for reliable multicast transmission", in Proc. SIGCOMM'97, Cannes, setembro de 1997.

[2] D. A. M. Villela e O. C. M. B. Duarte, "A priority scheme applied to scalable reliable multicast communications", in IEEE Global Telecommunications Conference GLOBECOM'98, Sydney, Australia, pp. 33683373, novembro de 1998.

[3] S. Pingali, D. Towsley e J. Kurose, "A comparison of sender-initiated and receiver initiated reliable multicast protocols", IEEE Journal on Selected Areas in Communications, vol. 15, no. 3, abril de 1997.

[4] H. M. de Lima e O. C. M. B. Duarte, "An effective selective repeat ARQ strategy for high speed point-tomultipont communications", in IEEE Global Telecommunications Conference GLOBECOM'96, pp. 10591063, novembro de 1995.

[5] H. M. de Lima e O. C. M. B. Duarte, "Point-tomultipoint SR ARQ scheme with accumulative acknowledgment for satellite communications", Computer Networks and ISDN Systems, vol. 30, no. 14, pp. 13111315, agosto de 1998.

[6] W. A. Doeringer, D. Dykeman, M.Kaiserwerth, B. W. Meister, H. Rudin e R. Williamson, "A survey of lightweight transport protocol for high-speed networks", IEEE Transactions on Communications, vol. COM-38, no. 11, pp. 2025-2038, novembro de 1990.
[7] A. R. K. Sastry, "Improving repeat-request (ARQ) performance on satellite channels under high error rate conditions", IEEE Transactions on Communications, vol. COM-23, no. 4, pp. 436-439, abril de 1975.

[8] N. D. Birrel, "Pre-emptive retransmission for communication over noisy channels", IEE Proceedings, Part F, vol. 128, pp. 393-400, novembro de 1981.

[9] M. Moeneclaey e H. Brunneel, "Efficient ARQ scheme for high error rate channels", Electronic Letters, vol. 20, no. 23, pp. 986-987, novembro de 1984.

[10] M. Moeneclaey, H. Bruneel, I. Bruyland e D. Y. Chung, "Throughput optimization for generalized stop-andwait ARQ scheme", IEEE Transactions on Communications, vol. COM-34, no. 2, pp. 205-207, fevereiro de 1986.

[11] J. M. Morris, "On another Go-Back-N ARQ technique for high error rate conditions", IEEE Transactions on Communications, vol. COM-26, no. 1, pp. 187-189, janeiro de 1978.

[12] H. M. de Lima e O. C. M. B. Duarte. "Um protocolo de retransmissão contínua para comunicação de dados a alta velocidade", in V Simpósio Brasileiro de Microondas e X Simpósio Brasileiro de Telecomunicações TELEMO92, Brasilia, DF, pp. 439-444, julho de 1992.

[13] H. M. de Lima e O. C. M. B. Duarte, "Performance of repeated retransmission $\mathrm{GB}(\mathrm{N})$ schemes for pointto-multipoint noisy channels", in 38th IEEE Midwest Symposium on Circuit and Systems, Rio de Janeiro, RJ, pp. 1-4, agosto de 1995.

[14] S. Lin e P. S. Yu, "An effective error control scheme for satellite communications", IEEE Transactions on Communications, vol. COM-28, no. 3, pp. 395-401, março de 1980.

[15] M. J. Miller e S. Lin, "The analysis of some selective repeat ARQ schemes with finite receiver buffer", IEEE Transactions on Communications, vol. COM-29, no. 9, pp. 1307-1315, setembro de 1981.

[16] E. Weldon, "An improved selective repeat ARQ strategy", IEEE Transactions on Communications, vol. COM-30, no. 3, pp. 480 -486, março de 1982.

[17] Y. Chang e C. Leung, "On Weldon's ARQ strategy", IEEE Transactions on Communications, vol. COM-32, no. 3, pp. 297-300, março de 1984.

[18] D. Towsley e S. Mithal, "A selective repeat ARQ protocol for a point to multipoint channel", in IEEE International Conference on Communications INFOCOM'87, San Francisco, CA, pp. 521-526, abril de 1987.

[19] P. S. Yu e S. Lin, "An efficient selective repeat ARQ scheme for satellite channels and its throughput analysis", IEEE Transactions on Communications, vol. COM-29, no. 3, pp. 353-363, março de 1981.

[20] R. A. Howard, Dynamic Probabilistic Systems. John Wiley and Sons, 1971.

[21] H. M. de Lima e O. C. M. B. Duarte, "Um novo protocolo multiponto para comunicação via satélite a alta velocidade", in XI Simpósio Brasileiro de Redes de Com- 
putadores SBRC'93, Campinas, pp. 616-630, maio de 1993.

Heliomar Medeiros de Lima nasceu no Rio Grande do Norte em 1957.Graduou-se em Engenharia Eletrônica em cum laude pela Universidade Federal do Rio de Janeiro em 1982. Recebeu os títulos de Mestre e de Doutor em Engenharia Elétrica pela Coordenação dos Programas de Pósgraduação em Engenharia da Universidade Federal do Rio de Janeiro em 1987 e 1994, respectivamente. É funcionário do Banco do Brasil atuando como analista de telecomunicações. Seus principais interesses em pesquisa são em protocolos de alta velocidade, análise de desempenho e comunicações via satélite.

Otto Carlos Muniz Bandeira Duarte nasceu no Rio de Janeiro em 23 de outubro de 1953. Recebeu os diplomas de Engenheiro Eletrônico e de Mestre em Engenharia Elétrica pela Universidade Federal do Rio de Janeiro em 1976 e 1.981, respectivamente, e o título de Dr. Ing. pela École Nationale Supérieure des Télécommunications, França, em 1985. É professor da Universidade Federal do Rio de Janeiro desde 1978. Foi professor convidado da Universidade Paris 6 em 1999. Seus principais interesses em pesquisa são em protocolos de alta velocidade, comunicações multimídias, redes ativas, agentes móveis e qualidade de serviço na Internet. 